\title{
CRISIS Y DEUDA DE LA GRECIA CLÁSICA EN EL SIGLO V A.C.: LA ATENAS DE PERICLES VS LA ATENAS DE SYRIZA.
}

JAIME HERNÁN-PÉREZ AGUILERA ${ }^{1}$

Fecha de recepción: 21 de octubre de 2015

Fecha de aceptación: 22 de marzo de 2016

La humanidad no posee regla mejor de conducta que el conocimiento del pasado. Polibio; $\mathrm{H}^{\mathrm{a}}$ del ascenso de Roma, I, 1.

\section{I \\ INTRODUCCIÓN}

Una de las características más señaladas del populismo es la de destruir todo aquello que pretende solucionar, y cuando lo hace, utiliza con habilidad el recurso de echar la culpa a otro. Son los mercados o los especuladores los causantes del desorden económico y social, y no las medidas intervencionistas que terminan por arruinar la economía de mercado. El fenómeno del populismo no es reciente, la historia nos muestra con meridiana claridad cómo la Grecia de Pericles, la Roma de Trajano o de Diocleciano, entre otras, terminaron en una crisis social y económica sin precedentes por

\footnotetext{
${ }^{1}$ Doctor en Economía por la Universidad Rey Juan Carlos. Licenciado en Económicas por la Universidad Complutense. Licenciado en Historia por la UNED. Diploma en Estudios Avanzados de Historia Moderna por la UNED. Email: sercojaime@gmail. com
} 
recurrir a medidas populistas para obtener paz social a cambio de poder político.

Cualquier fenómeno social es de una extraordinaria complejidad, como lo es explicar la actual crisis griega o la crisis del Imperio Ateniense del siglo $v$ antes de Cristo (en adelante a.C.). Es probable que confluyan múltiples causas, lo que hace que la mayoría de historiadores y economistas rechacen una explicación monocausal y se centren en buscar distintas explicaciones. Una parte de estas explicaciones nos la puede aportar, sin duda alguna, el conocimiento histórico, por un lado, y la teoría económica, por otro, ya que si aplicamos una teoría económica previa podemos interpretar la historia ${ }^{2}$, y muchas veces observamos el paralelismo que surge en distintos momentos históricos como resultado de intervenir sobre la economía y la organización espontánea de la sociedad. ¿Se podría hacer una comparación buscando similitudes históricas entre dos épocas distintas? Estas serían, por un lado la Grecia Clásica del siglo v antes de Cristo, y por el otro la Grecia del euro. Este conocimiento histórico nos ofrece un certero análisis de las consecuencias negativas que tiene intervenir sobre los fenómenos sociales, como por ejemplo manipular los tipos de interés, la cantidad de dinero, sobre el recurso a la inflación, a las políticas de endeudamiento público, de subsidios, o a la fijación de precios y salarios, entre otras muchas. La Grecia del euro, y la Grecia del Imperio Ateniense, a pesar del evidente lapso en el tiempo, pueden ser dos comparaciones efectivas.

La historia es un relato continuo de la acción humana, es un esfuerzo consciente de adaptación del ser humano para reemplazar condiciones menos satisfactorias por otras mejores y la historia como ciencia social se fija en el análisis de las civilizaciones pasadas y modernas. La civilización es un producto del esfuerzo humano, y la Grecia actual, como la Grecia Clásica, es el logro de hombres deseosos de combatir las fuerzas contrarias a su bienestar. Este logro depende de que los hombres usen medios adecuados para poder

\footnotetext{
${ }^{2}$ Carl Menger insistió en la imposibilidad de extraer leyes económicas a partir de un conocimiento de la historia, en pleno debate con Smoller y la Escuela Historicista de Alemania, dentro de la «Methodenstreit» o la polémica de los métodos. Carl Menger (2006), El método de las ciencias sociales, Madrid, Unión Editorial.
} 
alcanzar sus propias metas y sus propios fines. Si los medios elegidos no son idóneos para alcanzar los fines que se persiguen, el desastre es inevitable.

Grecia en la actualidad es un país quebrado, con una de las economías europeas más pobres, menos productivas y más intervencionistas $^{3}$, con uno de los mayores niveles de gasto público, que aumentó entre 1996 y 2008 un 80\%. Por no hablar el desbocado e insostenible sector público. Sus políticas destinadas a gasto social entre 1996 y 2012 han pasado del 24,6\% al 31,1 \% del PIB. Este gasto público se financió emitiendo deuda, deuda que a su vez se financiaba gracias a una burbuja crediticia que se extendió por la zona euro derivada de una relajación de la política monetaria del BCE. La hipertrofia del Estado griego no tiene parangón en las economías modernas, si antes de la crisis del euro la deuda representaba ya el 250\% de los ingresos públicos, en el año 2011 esta llegó a representar el 400\%. En el año 2009, el déficit público representaba ya el $14 \%$, llegando a alcanzar el $17 \%$ antes del primer rescate.

Ante la situación actual de Grecia nos surge una pregunta: ¿a lo largo de su dilatada historia, ha existido algún periodo que guarde algún paralelismo con el pasado? ¿Puede mostrar este pasado un ejemplo de lo que ocurre cuando el Estado interviene en prácticamente cualquier esfera de la libertad económica e individual? Aunque las sociedades, los recursos disponibles, las ideologías y los métodos de producción son diferentes en cada momento y época histórica, siempre se puede hacer un evidente ejercicio de análisis, comparación y comprensión para obtener resultados y verificar si la teoría económica es válida.

El intervencionismo estatal trata de promover la participación de la autoridad pública en el proceso de la economía, asumiendo la gestión directa de determinadas áreas de la producción, para alentar o desalentar ciertas actividades según su criterio social, o para restituir la libre competencia cuando ésta se ha perdido por la acción monopolista, o redistribuir la riqueza utilizando para ello el sistema tributario y la seguridad social como instrumentos. En

\footnotetext{
${ }^{3}$ En el Índice de Libertad económica del Heritage Foundatión y The Wall Street Journal ocupaba el puesto 100 en el ranking mundial por la facilidad para hacer negocios cuando estalló la crisis del euro.
} 
casos extremos, la intervención estatal puede llegar a la estatificación de los instrumentos de producción (tierras, minas, fábricas, servicios, etc.) como en la experiencia marxista de las décadas pasadas. Hay una muy amplia gama de posibilidades en el campo del intervencionismo estatal, que va desde la tenue regulación del proceso económico y la utilización de los instrumentos tributarios, monetarios, crediticios y cambiarios para asignar recursos a las actividades productivas que interesa impulsar o desalentar, hasta la estatificación total de los medios de producción, la planificación centralizada y la supresión del derecho de propiedad privada, tal como se experimentó en los regímenes marxistas.

Todas las naciones europeas, especialmente con la crisis, se han empeñado en otorgar más poder a sus gobiernos, sometiendo al Estado la mayoría de las actividades y esfuerzos humanos, y Grecia desde luego no es una excepción. Un gobierno no produce nada en absoluto, el Estado no puede conseguir ni un céntimo de nadie sin quitárselo a otra persona o a otra empresa, y que esta última persona o empresa, que casualmente es alguien que ha producido ese dinero, ahora no puede decidir si lo gasta o por el contrario lo ahorra.

El intervencionismo del Imperio Ateniense del siglo v a.C. se manifestaba en unas crecientes necesidades financieras para mantener la flota y el aparato burocrático y coercitivo, que exigía un mayor consumo de trabajo y bienes en forma de tributos, lo que repercutía sobre el bienestar de los ciudadanos de la Liga especialmente, y en menor medida sobre los atenienses, al reducir su renta, pero sobre todo porque este intervencionismo fiscal estaba distorsionando la cantidad y la distribución de lo que se producía.

Un análisis histórico de las crisis es un requisito imprescindible para entender lo que acontece en la actualidad. Cada época histórica tiene sus crisis, de hecho los periodos económicamente depresivos son un rasgo histórico recurrente en cualquier sociedad, de la antigüedad clásica o de la Europa moderna. Lo que las hace diferentes son las diferentes fases de desarrollo que los sistemas económicos presentan, de manera que a lo largo de la historia acontece un tipo particular de crisis en cada momento, centrada en determinados sectores y con manifestaciones y efectos diferentes, tanto en el alcance como en su profundidad. La crisis de la Grecia Clásica en el 
siglo $v$ a.C. y la actual tienen sin duda un punto en común, el masivo intervencionismo estatal y las políticas de corte populista.

II

\section{LAS POLIS GRIEGAS: EL ORIGEN ESPONTANEO Y NO DIRIGIDO DE LAS CIUDADES ESTADO GRIEGAS}

Las polis o ciudades-estado griegas eran comunidades de ciudadanos que otorgaban una enorme importancia a la ley, pues era esta la que regulaba las relaciones entre todos ellos, era el nexo de unión por el que toda la comunidad quedaba involucrada de una manera u otra, de hecho, muchas ciudades inscribían sus leyes, decretos y tratados en piedra o placas de metal y las dejaban expuestas para ofrecer así visibilidad a las leyes, a su respeto, y sobre todo para fomentar la propia relevancia de ser ciudadano de la polis. Las polis griegas eran cercanas entre sí, tenían una lengua común, bienes comunes, y sobre todo una cultura común, pero a pesar de todo, sus ciudadanos vivían en una enorme y compleja variedad de sistemas políticos y de actividades económicas. Así por ejemplo, Corinto se gobernaba por una oligarquía cuya constitución limitaba los derechos políticos a una pequeña minoría de propietarios, mientras que Atenas y sus ciudadanos estaban sujetos a leyes y costumbres de la democracia radical, con una constitución que concedía amplios poderes a un extenso cuerpo de ciudadanos varones.

En el siglo VIII a.C. la mayoría de las polis eran gobernadas por aristócratas, pero a partir de los siglos VII y VI a.C. se produce un complejo y profundo cambio en el poder, las leyes y las estructuras sociales. La transformación de la ciudad estado griega desde una monarquía a una oligarquía y posteriormente a una democracia ocurrió como consecuencia de la tecnología militar, al necesitar la falange un ejército de ciudadanos. Fue este el precio que pagó el gobernante, la disolución de sus poderes en asambleas, para hacer frente a esta contingencia, pero este cambio sentó las bases de la formación de nuevas formas de hacer política ${ }^{4}$.

\footnotetext{
${ }^{4}$ En la Europa moderna, las modificaciones en la tecnología militar asociadas a la pólvora y los ejércitos profesionales llevaron a la cesión de poderes a Parlamentos y/o
} 
El corazón de la actividad económica y comercial de las polis era el Agora. Estaba conformado por un conjunto de edificios públicos que concentraba la vida de la ciudad, donde compradores y vendedores negociaban. Se trataba efectivamente de un mercado, aunque no de una economía de mercado en el sentido del término. De hecho, el uso del dinero en las transacciones comerciales, bajo la forma de monedas de plata, formaba parte de la vida económica, más como elemento de intercambio que como reserva de valor ${ }^{5}$. Los precios fluctuaban de acuerdo a las condiciones de la oferta y la demanda, pero las posibilidades que ofrecía el regateo atenuaban las oscilaciones. El Agora era un mercado donde se expresaba la categoría social y el poder de los negociantes, era un lugar en el que se reafirmaba el poder y el status social.

El comercio era vital para las polis griegas. Los desequilibrios permanentes en materias primas, y las variaciones climáticas que acontecían sobre la producción de cereales básicos forzaban a las ciudades estado griegas al comercio y al intercambio. Además contaban con un territorio y con unos recursos limitados básicamente a la tierra, que escasamente remediaba sus necesidades básicas. Como en cualquier economía agraria de subsistencia, la recurrente escasez alimentaria que derivaba de una presión demográfica ante la pérdida de la cosecha, fomentaba como solución viable más la exportación de personas que la importación de alimentos. Sin embargo, durante la mayor parte de los siglos v y IV a.C. Atenas fue capaz de sufragar importaciones de cereales para mantener a una población que excedía ampliamente la capacidad productora de su territorio. La riqueza que proporcionaba el comercio a larga distancia lo hizo posible. Grecia en el siglo v a.C. disponía de una agricultura comercializada, del comercio a grandes distancias, y mante-

Estados Generales, como respuesta a la necesidad de mayores ingresos con los que poder financiar las necesidades del Estado. G. Parker (2002), La revolución militar. Innovación militar y apogeo de Occidente 1500-1800, Madrid, Alianza editorial.

${ }^{5}$ Carl Menger insistirá desde el inicio que el dinero no surge por arte de magia, sino como consecuencia de decisiones que han sido tomadas racionalmente por quienes están directamente interesados en hacer uso del mismo. Así surgió en Lidia, en la Grecia Antigua, a consecuencia de los intercambios de bienes, de manera espontánea y a través de un largo proceso de selección, sin que el Estado intervenga en ello. Carl Menger, El dinero, Unión Editorial, Madrid, 2014 
nía una complicada rivalidad política y comercial contra las principales polis, como Esparta o Tebas, y fundamentalmente contra el Imperio Persa. Por encima de todas las ciudades-estado o polis que conformaban Grecia, destacaba una de ellas, Atenas.

III

GRECIA EN EL SIGLO V A.C.

\section{LA LIGA DÉLICA Y LA CREACIÓN DEL IMPERIO ATENIENSE}

Atenas domina las narraciones políticas y militares del siglo $\mathrm{v}$ en un grado superior al de periodos anteriores de la historia griega. Ello no es solo consecuencia de la concentración de fuentes e información con origen o destino en la ciudad, sino también a que los atenienses crearon el primer imperio de Occidente, lo cual afectó al resto de polis griegas.

Grecia tuvo que afrontar el expansionismo del Imperio Persa con audacia y flexibilidad. Sin duda, su propia configuración en un conjunto de polis, cada una con sus instituciones, normas y conductas, permitió ofrecer mayor resistencia al invasor persa. El Imperio Persa había estado expandiéndose hacia el occidente europeo, sometió Tracia y Macedonia, y se dirigió hacia Atenas. Sin embargo, la ciudad, asistida por Platea, venció a los persas en Maratón. Los persas no desistieron y Jerjes ${ }^{6}$, hijo de Darío, volvió a invadir Grecia. Atenas tenía el prestigio de su victoria en Maratón, pero la gran potencia militar era Esparta. Ambas ciudades, ante las dimensiones del ejército persa, decidieron colaborar y formaron una unidad panhelénica. Las dimensiones de la misma fueron mas bien modestas, pues de las aproximadamente 1.000 polis griegas que había, solo unas treinta enviaron delegados al consejo celebrado en el istmo de Corinto. Esparta hizo frente al invasor en la batalla de las Termópilas, mientras Atenas venció en Salamina por mar. De esta manera el peligro persa fue conjurado, pero nacía

\footnotetext{
${ }^{6}$ Jerjes I (cerca 519 a.C.-465 a.C.) trató de vengar la derrota sufrida por su padre, Darío I, en la batalla de Maratón, durante la Primera Guerra Médica (490a. C.).

${ }^{7}$ Darío I, llamado El Grande (522 a.C.-488 a.C.) rey de Persia, comenzó la guerra contra las ciudades griegas invadiendo Tracia y Macedonia.
} 
una nueva amenaza, esta vez la lucha sería por el control del nuevo panhelenismo entre Atenas y Esparta.

La experiencia de las Guerras Médicas logró que los griegos pasaran a verse como un grupo homogéneo que compartían unas creencias y unos valores fundamentales. El centro de este nuevo espíritu panhelénico estaba dominado por dos compromisos: la eleuthería o libertad política, y la obediencia al nomos, es decir, a la ley. Es importante tener presente esta idea, porque a medida que el intervencionismo político y económico del Imperio Ateniense se fue extendiendo, las leyes en sentido tradicional dejarían de actuar como normas de referencia para el comportamiento individual, y su papel lo iba a representar en este caso el gobierno de aristócratas, oligarcas e incluso demócratas radicales que como veremos, utilizaron la asamblea y la oratoria para gobernar. Curiosamente estos valores de libertad política y respeto a la ley eran opuestos a los persas y a todos aquellos que vivían bajo el dominio de gobernantes autocráticos a los que debían obediencia absoluta. Sin embargo, la libertad de los griegos sería repetidamente secuestrada por gobernantes.

La victoria de Salamina y el poder militar ateniense terminaron por formar un arkhé o poder naval. Terminada la invasión persa, en la primavera del año 478 a.C. cincuenta barcos de la Liga Helénica liberaron a las polis griegas de Chipre y pusieron cerco a Bizancio. La flota, al mando del general espartano Pausanias, afrentó a los jonios, y el mando pasó a los atenienses. Así nacía la Liga Délica ${ }^{8}$. Bajo la jefatura de Atenas, reunía a las ciudades griegas autónomas, todas con el mismo derecho de voto, con el objetivo expreso de defenderse de los persas y de mantener la libertad de Grecia. Esta liga, a diferencia de las anteriores, no era terrestre sino de carácter naval, y aquí radicaba uno de sus principales problemas: por ser naval requería una enorme suma de capital. Los remeros y la tripulación no solían estar sujetos a una movilización forzosa, no aceptaban servir en las naves sino era a cambio de un salario, o como mínimo si se les garantizaba su subsistencia. La flota requería a su vez un mantenimiento continuado y costoso, y la construc-

${ }^{8}$ La Liga Délica, así llamada por los historiadores modernos, recibe ese nombre debido a que su tesoro se custodiaba en la isla de Delos, consagrada al dios Apolo. 
ción de nuevos barcos necesitaba la creación de nuevas y onerosas instalaciones portuarias, incluyendo diques y astilleros. Por otra parte, la tecnología militar se complicaba cada vez más, de manera que los gastos en maquinaria y fortificación presionaban más la capacidad financiera de Atenas. La introducción de la soldada hizo posible intensificar la potencia naval y alargar las expediciones comerciales o militares, pero a cambio la inversión pública necesaria para hacer frente a todo este esfuerzo fue cada vez más exigente.

La Liga Délica necesitaba inversión pública, gasto público que lógicamente había que financiar. Los atenienses encontraron en el phoros o tributos la fuente de financiación. Era una contribución financiera anual que aportaban casi todos los estados miembros de la liga. Los tesoreros encargados de recibir y administrar los tributos estaban copados por atenienses, Atenas por lo tanto controlaba los fondos de la Liga, pero además, los aliados comenzaron a pagar este tributo para garantizarse protección, siendo los pagos unas veces en servicios anuales o barcos, y otras en dinero. Desconocemos con precisión la carga que podía suponer el pago a los aliados, se determinaría en gran medida a partir de los recursos locales y sobre todo de la tierra, pero dada la relativa pobreza de la mayoría de las polis griegas, cualquier expropiación continuada de sus recursos debía tener un efecto negativo sobre su prosperidad económica.

Atenas se transformó en el organizador político y económico de la Liga. En los primeros años sus campañas se dirigieron contra estados griegos, como Naxos, que pretendía abandonarla, o contra Caristo, para obligarla a formar parte de ella. A mediados de siglo Atenas controlaba cerca de ciento cincuenta polis, colocaba en las ciudades oficiales encargados de asegurar la lealtad de la polis, interviniendo sobre su autonomía política y judicial si era necesario, llegando incluso a emplear la fuerza cuando los remedios anteriores no eran suficientes. De esta manera, las polis veían cómo menguaban sus medios económicos y cómo intervenía una autoridad superior sobre cualquier ejercicio posible de libertad económica.

Las crecientes necesidades de financiación del Imperio Ateniense afectaron por igual a todos los miembros de la Liga. En concepto de tributos, los atenienses recibirían unos 400 talentos 
anuales. Además había otros recursos adicionales de financiación, como eran la apropiación de tierras de los aliados, que se consagraban a la diosa Atenea y que por lo tanto conllevaban impuestos adicionales, o bien se cedían para el arrendamiento de atenienses. El comercio entre ciudades de la Liga se intensificó, sin embargo, frente a las ciudades rivales al no estar integradas en ella las exportaciones sufrieron un importante descenso. Hasta donde fueron capaces, los atenienses controlaron las importaciones de cereales que pasaban por el Mar Negro y por el Helesponto, recaudando tasas de tránsito sobre las cargas destinadas a las ciudades del imperio. Además se evidencian intentos de imponer a los aliados la moneda y los estándares áticos de pesos y medidas, como paso a la creación de un sistema económico cerrado y autárquico.

\section{IV \\ IMPERIO Y DEMOCRACIA: LA FIGURA POLÍTICA DE PERICLES}

El Imperio Ateniense y la democracia se desarrollaron en paralelo. El origen de la democracia ateniense se suele establecer hacia el año 508 a.C. con las reformas de Clístenes ${ }^{9}$. Es importante resaltar que los hombres que dieron a Atenas su dominio del mundo griego no provenían de la élite dirigente, sino de los soldados hoplitas que habían luchado en Maratón o en los trirremes que combatieron en Salamina. Después de las Guerras Médicas se otorgó a la ciudadanía masculina, al conjunto del demos, una mayor cuota de participación ciudadana, de forma que a mediados del siglo $\mathrm{v}$ a.C., la asamblea era soberana y las instituciones que antes representaban el poder resultaron debilitadas. Los ciudadanos desempeñaban estos cargos por sorteo y la mayoría recibía un salario a cambio de sus servicios.

\footnotetext{
${ }^{9}$ Clístenes de Atenas (570-507 a.C.) de la familia de los Alcmeónidas, introdujo el gobierno democrático en Atenas sobre las bases de la isonomía o igualdad de los ciudadanos ante la ley, menospreciando los derechos en virtud de la herencia familiar (aristocracia) o de la riqueza (timocracia). Sería la «Ekklesía» o Asamblea de ciudadanos la que tendría la última palabra y se convertiría en el órgano de decisión de todos los ámbitos.
} 
¿Cómo fue posible este equilibrio político? Los ciudadanos deseaban la arkhé o poder naval porque proporcionaba beneficios inmediatos, riqueza y poder a la ciudad mientras que la élite, a cambio cedía estas ventajas o precio en forma de democracia. Es obvio que los atenienses se habían dado perfecta cuenta que los ingresos de la Liga eran en ese momento muy superiores a las necesidades militares, y esta riqueza les proporcionaría la manera de invertir en su ciudad: Atenas se iba a lanzar a un programa constructor inmenso, un colosal programa de obras públicas. Su promotor no sería otro que Pericles.

Pericles, al igual que otros muchos políticos y personajes históricos, se ha visto sin duda beneficiado por la historiografía, una historiografía tradicional, que en cierta manera, se ha dejado influir por la época de grandeza artística y política que aconteció en torno a la ciudad de Atenas en el siglo v a.C. y que es, en cierto modo, el origen de nuestra cultura occidental.

Pericles nació a mediados de la década de 490 a.C. Su padre, Jantipo, era noble, al igual que su madre. Su carácter sin duda se vio influenciado por los cambios que acontecieron en Atenas a lo largo de su juventud: la preeminencia política y comercial que adquirió la ciudad, y el asentamiento de la democracia a raíz de las reformas que efectuó Clístenes. Por aquel entonces, la democracia ateniense era el marco idóneo para que un político hiciera carrera. Allá por la década de 480 a.C., se intensificó la actividad popular, y una oleada de ostracismos reflejó como nada lo manipulable que podía ser el pueblo en beneficio propio, de hecho el propio padre de Pericles en el año 489 a.C. había aprovechado la opinión pública para cargar contra Milciades ${ }^{10}$, el héroe de la batalla de Maratón. La reforma de Clístenes había provocado que el voto mayoritario del pueblo era el que decidía lo que había que hacer, por lo tanto, todo aquel que controlase en su propio beneficio la confianza del pueblo podía ser más

${ }^{10}$ Milciades II el Joven, también llamado Maratonómaco (hacia 550-488 a.C., fue un político y general ateniense, fue gobernador del Quersoneso Tracio, una región que era crítica para el abastecimiento de trigo de la ciudad de Atenas. Durante el conflicto con el Imperio Persa, libró diversas batallas, siendo célebre la batalla de Maratón. Después de la campaña militar de Paros fue procesado en Atenas por traición aunque posteriormente fue rehabilitado, muriendo a consecuencia de las heridas recibidas al finalizar la campaña de Paros. 
eficaz que cualquiera de los aristócratas o militares más afamados. Esta confianza solo se podía ganar con la oratoria, y realizando propuestas a la asamblea medidas que resultaran atractivas.

La figura de Pericles y la valoración de su obra política, económica y militar ha suscitado controversias e intensos debates. Sarah Ruden ${ }^{11}$ considera a Pericles un populista, un demagogo e incluso lo que hoy consideramos como un «halcón de la política». Victor L. Ehrenberg considera que fue el imperialismo ateniense encarnado en su figura el origen de la negación de la democracia y de las libertades del resto de polis griegas ${ }^{12}$. Por el contrario, Donald Kagan ${ }^{13}$ valora a Pericles mejor político que estratega.

Para los escritores y pensadores clásicos de la antigüedad, Pericles suscitó la misma intensidad en el debate en torno a su política. Tucídides $^{14}$, político y militar contemporáneo del propio Pericles, veneraba su oratoria, su inteligencia, su inmunidad ante los sobornos y la corrupción, pero sobre todo su capacidad para controlar al pueblo, así dice que «no era arrastrado por el pueblo, sino que era él quién los guiaba ${ }^{15}{ }$. Por el contrario, Platón, que por otra parte no era un demócrata, consideraba a Pericles un demagogo adulador que dirigía a los atenienses al desastre, y así comentaba que: «Hasta donde yo se, Pericles convirtió a los atenienses en gente perezosa, avariciosa y chismosa, al comenzar el sistema de pagos públicos ${ }^{16}{ }^{\text {». }}$ Quizás el retrato más sugerente es el de Ión de Quíos, que sin ser ateniense, encontró a Pericles «presuntuoso y algo vanidoso, y que con sus jactancias se combinaba un gran desdén y desprecio por los demás ${ }^{17}$ ».

${ }^{11}$ S. Ruden: Lysistrata, 80.

${ }^{12}$ V. L. Ehrenberg: From Solón to Sócrates, 332.

${ }^{13}$ D. Kagan: The Archidamian War, 28, 41.

${ }^{14}$ Tucídides (hacia 460-395 a.C.) historiador griego, fue nombrado estratego de Atenas y se le confió el mando de la flota para romper el asedio de Anfípolis, pero fracasó y fue condenado al exilio por la ciudad. Autor de la Historia de la Guerra del Peloponeso, presenta este conflicto como una lucha entre Atenas y Esparta, provocado por el expansionismo ateniense, basando su narración no en la intervención de los dioses, sino en los actos humanos, en definitiva, sobre la acción humana.

15 Tucídides, Discurso fúnebre de Pericles, II, 65.

${ }^{16}$ Platón: Gorgias, $515 \mathrm{e}$.

${ }^{17}$ La hostilidad de Ión de Quíos hacia Pericles debe ponerse en el contexto del trato dado por loa atenienses a Quíos durante la guerra samia. Además Ión tenía amis- 
Fueron sus habilidades oratorias imprescindibles tanto para convencer como para controlar la asamblea, el verdadero centro de poder de Atenas. Diodoro de Sicilia dice que «sobresalió sobre todos sus compatriotas en capacidad oratoria» ${ }^{18}$, mientras que de nuevo Ion de Quios decía que tenía «una forma presuntuosa y algo arrogante de dirigirse» incluso acusándole de desdén y falta de respeto hacia los demás ${ }^{19}$. Platón en su diálogo Gorgias le considera como ejemplo de poderosa oratoria mientras que en Menexeno se burlaba de la misma ${ }^{20}$. Más recientemente, Richard C. Jebb concluye que «Pericles debió de haber sido también único como orador $»^{21}$. Pericles era consciente de tener unos proyectos y unas responsabilidades nada comunes. La política se hacía en la calle, era un asunto que le ocupaba a uno todo el tiempo. Además supo rodearse de un grupo de amigos intelectuales, como el músico Damón o el filósofo Anaxágoras ${ }^{22}$, e incluso cultivó algo más que su amistad con Aspasia, su famosa amante.

Desde la caída de Cimon $^{23}$ y la muerte violenta de Efialtes ${ }^{24}$ en el 461 a.C., fue Pericles el centro del Estado ateniense. Sometido al ostracismo a su rival Tucídides, fue elegido estratego año tras año, cargo que le daba el soporte de su autoridad real ante el pueblo ateniense y le convertía en líder político supremo por encima de

tad con Cimón. Ión en Plutarco, Vidas paralelas, Vida de Pericles, 5, 3, Editorial Gredos.

${ }_{18}$ Diodorus, XII, 39. Diodoro Sículo o de Sicilia fue un historiador griego del siglo I a. C. nacido en Agirio, Sicilia. Su monumental obra, Biblioteca Histórica, consta de 40 volúmenes divididos en tres secciones. Los libros VII a XVII cuentan la Historia del mundo desde la Guerra de Troya hasta la muerte de Alejandro Magno.

19 Plutarco: Pericles.

${ }^{20}$ Platón: Gorgias, 455d y Menexenus, $236^{\mathrm{a}}$.

${ }^{21}$ Sir Richard C. Jebb, The Attic Orators.

${ }^{22}$ Anaxagoras (500-428 a.C.) fue un filósofo presocrático que introdujo la noción de nous o pensamiento como elemento fundamental de su concepción física. Pericles, Tucídides e incluso Socrates fueron sus alumnos.

${ }^{23}$ Cimón de Atenas (510-450 a.C.) fue estratego repetidas veces, la primera en 478 a. C.. Dispuso del favor popular y también del apoyo de las grandes familias nobles, lo que le confirió un peso importante para la conducción de las campañas militares. Su política filoespartana le enfrentó con Efialtes y posteriormente con Pericles.

${ }^{24}$ Efialtes (hacia el 461 a. C.), fue un antiguo político ateniense del siglo v a. C., que se convirtió en el jefe del partido democrático de Atenas a y que se opuso al aristócrata Cimón, cabeza del partido aristocrático. Junto con Pericles, emprendió una serie de reformas políticas y sociales. 
todos sus rivales. El mismo Tucídides, apartado del poder por Pericles, describía el régimen de Atenas como una democracia solo de nombre ${ }^{25}$, pero en realidad era el gobierno de su primer ciudadano. En definitiva, Pericles conducía a su pueblo en la Asamblea de la ciudad gracias a sus amplias y cuidadas dotes oratorias, a un efectivo control del poder y al recurso de la asistencia social y financiera de amplias capas de la sociedad.

En política exterior, los atenienses siguieron las líneas trazadas por Temístocles mas que por Pericles. Firmaron la paz con el rey de Persia en el 450-449 a.C. y se firmaron tratados de alianza con los griegos de Occidente. Esta expansión ateniense chocaba con el poder de las ciudades del norte del Peloponeso, aliadas de Esparta. La experiencia militar acumulada durante las guerras Médicas contra el Imperio Persa, y el conflicto con Esparta y sus aliados en los años 460 y 446 a.C. le habían convencido que la superioridad estratégica de Atenas residía en su flota marítima, y en los inexpugnables Muros Largos, que defendían la ciudad de Atenas ante cualquier posible invasión.

La política interior de Pericles se hizo peligrosa y verdaderamente funesta para el futuro de la ciudad de Atenas. El control de los derechos de ciudadanía fue el primer paso para centralizar el poder, de manera que cuanto más radical se hacía la democracia ática, más intolerante se comportaba con los grupos de gentes que no tenían plenos derechos ciudadanos. Para evitar los posibles conflictos derivados de perder la participación en las decisiones del poder político, el Estado Social de Pericles comenzaría a ofrecer a los más pobres de los ciudadanos dietas y distribuciones de trigo, haciendo al pueblo ciego ante cualquier perjuicio que resultase de tal medida ${ }^{26}$. Así, los productores de trigo comenzaron a recibir presiones para vender sus cosechas a precios inferiores, desincentivando la producción y cualquier posible mejora técnica para aumentar la productividad de la tierra. En realidad, se estaba ge-

25 Tucídides (2006), Historia de la Guerra del Peloponeso, Libro II, 65, 9, Madrid, Editorial Gredos.

${ }^{26}$ Estas distribuciones de trigo gratuito se conocerían como «annona» en el Imperio Romano. Se trataba de controlar el poder, a costa de destruir el incentivo que tenía el agricultor para producir del modo más rentable, en mayor cantidad y a mejor precio. Como vemos, los gobernantes romanos copiaron eficazmente el modelo populista. 
nerando una deliberada acción política para producir una transformación del Estado enormemente trascendental: se pasó de un Estado de producción a un Estado de asistencia y beneficencia. La introducción de la llamada dieta, debida a la democracia radical de Efialtes, corrompió poco a poco a una buena parte de los ciudadanos, que acostumbrándose a las pensiones y los subsidios, abandonaron los trabajos productivos. Para alimentar a las gentes más pobres que carecía de tierra para trabajar, pero también con manifiestos fines de política expansiva en el ámbito de la Liga Ateniense, se utilizó el envío de ciudadanos a las colonias.

Una vez controlada la asamblea y transformado el estado, el despliegue de políticas populistas hicieron el resto. Pericles se lanzó a ofrecer trabajo y prosperidad mediante un ambicioso programa de obras públicas de carácter civil y militar. El primero de ellos, y dada la urgencia de protegerse frente a una posible invasión persa, fue recuperar el plan de fortificación y defensa ideado por Temístocles. Atenas, unida al Pireo y al Falero por la llamada muralla del Norte y por la muralla del Falero, se convirtió en una inexpugnable fortaleza. Posteriormente se añadió otro tercer muro, el Mediano, paralelo al del Pireo. El puerto del Pireo con sus tres ensenadas fue firmemente fortificado, reforzado con bastiones y torres, todo para proteger los astilleros y los trirremes atenienses. A los gastos de construcción y refuerzo de las defensas y murallas, se añadieron los gastos monumentales.

Las dos ocupaciones persas de los años 480 y 479 a.C. habían dejado poco del antiguo esplendor de los Pisistrátidas. Muchos templos estaban destruidos o dañados por los efectos del conflicto. Cimón ${ }^{27}$ ya había comenzado la construcción de nuevos edificios, como el llamado Pórtico de Hermes y el Teseón, que albergaba los supuestos restos de $\mathrm{Teseo}^{28}$. Su cuñado Pisianacte levantó la Stoa Poikilé, adornándola con pinturas de Polignoto, Micón y Paneno. Todo esto fue un pequeño esfuerzo de lo que iba a venir.

${ }^{27}$ Cimón de Atenas (hacia 510-450 a.C.) fue un político y general ateniense, partidario de una política proespartana, se opuso a los dos grandes políticos atenienses, Temístocles y sobre todo Pericles, hecho que se condujo al ostracismo en el 461 a.C. aunque siete años después pudo regresar a Atenas.

${ }^{28}$ Teseo, mítico rey de Atenas, fue el héroe que derrotó al Minotauro en el laberinto. 
Pericles se apoyó en las cuotas de los aliados al tesoro federal para emprender un vasto programa constructor. Con la idea de embellecer la Acrópolis, retomó el plan de los Pisistrátidas pero con mucha mayor amplitud. Ensanchó los muros de la Acrópolis y como símbolo de la ciudad de Atenas se levantó el Partenón. Edificado con mármol pentélico que resplandecía a distancia, la mano de Fidias creó la augusta estatua de la diosa Atenea. Frente al Partenón se elevó el Erecteon, destinado a los festivales musicales. Atenas en pocos años se cubrió de un resplandor artificial provocado por el magnífico mármol empleado en los edificios, que ocultaba las estrechas y apretujadas calles de la ciudad.

Para la población de Atenas vino una época de prosperidad derivada del impulso constructor del gobierno de Pericles. Las edificaciones eran una fuente inagotable de trabajo. Plutarco esboza una colorida imagen de la ciudad ${ }^{29}$, donde artesanos, comerciantes y toda clase de oficios se ganaban la vida en la ejecución de las obras. Además describe cómo, cada oficio disponía de un número de jornaleros y peones, lo que puede ser en definitiva una descripción sintomática de una burbuja, o en su defecto, de una expansión artificial de la actividad económica.

A los gastos de la actividad constructora se le unieron los gastos militares, consecuencia del mantenimiento de una flota para frenar cualquier posible competencia, así como para financiar las expediciones de Chipre y Egipto, que terminaron por dejar las arcas del tesoro vacías. Ante esta situación Herodoto describió a los trirremes atenienses con acierto: «Estas naves fueron un germen de calamidades, tanto para los griegos como para los bárba$\operatorname{ros}^{30}{ }_{»}$. Debido a ello, Pericles recurrió al decreto de Calias (434-

${ }^{29}$ En efecto, dice Plutarco que «a los que tenían juventud y vigor, las expediciones les facilitaban holgados recursos gracias al dinero público; y en cuanto a la masa desorganizada y obrera ni quiso que se quedara sin participar en las ganancias, ni que las recibiera ociosa y sin hacer nada, por eso propuso decididamente al pueblo grandes proyectos de edificios y planes con implicación de muchos oficios sobre obras que requerían tiempo (...) y donde cada arte, lo mimo que un general con su propio ejército, tenía dispuesta en formación a la tropa de obreros no cualificados, que así servía de instrumento y cuerpo para prestar el servicio, las necesidades esparcían y distribuían el bienestar entre las personas (...)». Plutarco, Vidas paralelas, Tomo II, Pericles, 12, Madrid, Editorial Gredos.

${ }^{30}$ Herodoto de Halicarnaso (2000), Historias Libro V, 97,3. 
433 a.C.) para disponer de los recursos que ofrecía el tesoro de Atenea Poliade en Atenas, para tener de esta manera una fuente alternativa de gasto, una reserva monetaria a la que poder recurrir en caso de necesidad, que se hizo evidente cuando la política ateniense tomó una deriva hacia la Guerra del Peloponeso. Tucídides, buen conocedor de la persona y la política de Pericles, describe cómo Pericles:

(...) les exhortó (a los atenienses) a tener confianza dado que por lo general llegaban a la ciudad seiscientos talentos de tributo cada año de parte de los aliados, sin contar con los otros ingresos $^{31}$; además, en la Acrópolis todavía quedaban entonces seis mil talentos de plata acuñada (se había llegado a alcanzar la suma de nueve mil setecientos talentos, pero parte de ellos se había gastado en los Propileos ${ }^{32}$ de la Acrópolis, en otros edificios y en el sitio de Potidea ${ }^{33}$; por otra parte, en ofrendas privadas y públicas, en todos los utensilios sagrados empleados en las procesiones y en los juegos, en despojos de los medos, y en otros objetos semejantes, había en oro y plata sin acuñar no menos de quinientos talentos $(\ldots)^{34}$

No debió de ser suficiente, pues Tucídides sigue describiendo las riquezas que fueron gastadas por el gobierno de Pericles:

(...) Añadió todavía riquezas de otros templos nada despreciables, de las que podrían servirse; y en caso de verse completamente privados de todo, podrían recurrir incluso a las láminas de oro que revestían a la misma diosa; y les hizo ver que la estatua

\footnotetext{
${ }^{31}$ Aquí Tucídides se está refiriendo a los ingresos del Estado por las minas, aduanas, multas administrativas, etc. Los ciudadanos no pagaban impuestos directos, y estos ingresos se destinaban no solo a mantener los gastos de la ciudad, sino a equipamiento militar y gastos de mantenimiento de la flota. Tucídides, La Guerra del Peloponeso, Libro II, 13, 3, Editorial Gredos.

${ }^{32}$ Los Propileos es una entrada monumental de la Acrópolis, construida según el diseño del arquitecto Mnesicles entre los años 437 y 431 a.C.

${ }^{33}$ El sitio de Potidea es uno de los catalizadores de la Guerra del Peloponeso. El conflicto se debe a la rebelión contra Atenas y sus aliados de la ciudad de Potidea, Corinto y otros aliados de la Liga del Peloponeso, que encabezaba Esparta. Tucídides estima su coste en unos dos mil talentos. Tucídides, ibídem, Libro II, 70, 2 y III, 17, 3.

${ }^{34}$ Tucídides, ibídem, Libro II, 13, 4,5.
} 
tenía un peso de cuarenta talentos de oro puro, y que se podía coger todo $(. . .)^{35}$

Tucídides está haciendo referencia sin duda a la gran estatua crisoelefantina que realizó el escultor Fidias. Es decir, contando con las láminas de oro que recubrían la estatua de la diosa Atenea, obra de Fidias, en las fechas de su consagración, entre 447-446 y 438-437 a.C., la cantidad de oro disponible andaría entre los 750 y 850 talentos, comprendiendo el coste de otros materiales nobles como el marfil o el mármol.

Si aceptamos la descripción de Tucídides, la relación oro-plata era en ese momento de 14 a 1, de modo que 40 talentos de oro equivalían a 560 talentos de plata. Si aceptamos la cifra que da Filóco$\mathrm{ro}^{36}$, este da 44, lo que serían 616 talentos, cifra que parece más exacta que la que ofrecen los textos de Tucídides. Otros autores, como Diodoro Sículo ${ }^{37}$, comenta que Pericles gasto aproximadamente 4000 talentos en la construcción de los Propileos y en el asedio de Potidea. Aunque estas cantidades pueden parecer ciertamente exageradas y poco afinadas, la investigación moderna calcula según los investigadores el coste del Partenón en 460 talen$\operatorname{tos}^{38}$, o incluso ascendería a 680 talentos y los Propileos en torno a los 200 talentos, mientras que la estatua de la Diosa Atenea habría costado unos 750 talentos $^{39}$. A pesar de la más que evidente disparidad en las cifras, lo que sin duda resulta de todo ello es el colosal esfuerzo financiero que supuso para la economía ateniense.

La política de Pericles creó un estado asistencial con un componente militar y ofreció a sus ciudadanos una falsa seguridad económica. La introducción de las dietas, y la oferta de trabajo público

${ }_{35}$ Tucídides, ibídem, Libro II, 13, 4,5.

${ }^{36}$ Filócoro de Atenas (hacia 340-267/261 a.C.) escritor ateniense contemporáneo de Eratóstenes, es el autor de Atthis, una historia de Atenas desde los tiempos remotos hasta el año 262 a.C. Cf. F. Jacoby, FGr-Hist 328, F 121.

${ }^{37}$ Diodoro Sículo es autor de la Biblioteca Histórica, una obra de 40 volúmenes dividida en tres secciones, donde trata, entre otras, de la historia de Grecia, en la primera sección, libros IV a VI. Diodoro Sículo (2001), Biblioteca Histórica, Madrid, Editorial Gredos.

${ }^{38}$ Stanier, «The cost of the Partenon», Journ. Hell. St. 73 (1953), 68-76, 1953, pág. 73. Según el autor este ascendería a 469 talentos.

${ }^{39}$ Cf. Eddy (1977), The gold in the Athenas Parthenon, pág. 144. 
garantizó la paz social, mientras ésta tuvo un sostenimiento económico. A medida que las presiones financieras se hicieron más fuertes para mantener todo el aparato asistencial, y que la competencia tanto de Esparta como de otras potencias presionaban su economía, el recurso al refuerzo de la capacidad militar fue creciente. La crisis no tardaría en llegar, y esta vez iba a desembocar en la Guerra del Peloponeso.

\section{$\mathrm{V}$ \\ PERICLES Y ALEXIS TSIPRAS}

Las ideas económicas que nacen en los partidos populistas consideran que la economía dejada a si misma es un caos espantoso en el que sólo la intervención del Estado puede poner orden. El intervencionismo populista se acerca a cualquier fenómeno económico con una actitud llena de suspicacia y de un espíritu que se puede calificar de inquisitorial, dispuesto a rechazar sin mas cualquier liberalización o reforma si no se ajusta a su sentir ético y político, por lo tanto el Estado debe ejecutar las medidas necesarias para sustituir las distorsiones creadas por el desarrollo de la libertad económica por medidas útiles a la colectividad. A pesar de todo, lo que no se dan cuenta es que muchas veces el efecto que se persigue es justamente el contrario del que se recibe.

Friederich von Hayek en su obra La Fatal Arrogancia ${ }^{40}$ manifestaba una idea esclarecedora según la cual, siempre que mediante el ejercicio sistemático de la coacción del Estado se conceden ventajas o privilegios a determinados grupos o personas, se estaba violentando algún principio universal de derecho, de manera que el proceso espontáneo de cooperación social termina sufriendo graves y negativas consecuencias. Pericles o Alexis Tsipras ejercen una continua y sistemática política intervencionista sobre prácticamente cualquier parcela de la actividad económica, lo que pone de manifiesto la poderosa intuición que tuvo Hayek al considerar que siempre que se procede a la violación de un principio universal de

${ }^{40}$ F. von Hayek (1990), La fatal arrogancia: los errores del socialismo, p. 169, Madrid, Unión Editorial. 
derecho, por coacción y concesión del gobierno, habrán de aparecer después inexorablemente las consecuencias negativas de ello.

En el caso de la Grecia de Pericles, el intervencionismo comenzó controlando la asamblea o ekklesía de los ciudadanos para, ofreciendo subsidios y trabajo, garantizar la paz social y de esta manera sostenerse el poder, aunque a costa de elevar el gasto y por lo tanto las necesidades de inversión pública. Esta saldría de los tributos que pagaban los aliados de la Liga Délica, impuestos que en definitiva eran una carga contra la actividad económica y contra la prosperidad de los ciudadanos. Toda esta inversión pública tendría como destino, primero un programa defensa militar, y sobre todo, un ambicioso programa de obra pública, que dadas las necesidades financieras que exigía a la economía ateniense, pudo generar una pequeña burbuja especulativa y financiera, dadas las colosales necesidades de financiación que fueron necesarias. Por otra parte, el Imperio Ateniense trató por todos los medios de controlar las rutas comerciales, evitando la competencia de otras polis y sobre todo para garantizarse la lealtad de otras, en definitiva suponía que sus ciudadanos no podrían tener los mejores productos al menor precio. Si en los primeros tiempos de Grecia como dice Hesio$\mathrm{do}^{41}$ trabajar no era infamante, el comercio no delataba inferioridad social y la vocación del mercader resultaba honorable, en la Atenas de Pericles todo cambió hasta desembocar en una profunda crisis económica y social.

Con una visión en la distancia de Pericles, desde que Alexis Tsipras accedió al poder y su partido, Syriza, ha llevado a cabo sus propuestas en materia económica y social, el descalabro que han provocado a la ya de por si grave situación económica ha sido mayor. Una de las medidas estrellas que proponía Syriza era, sin duda alguna, elevar el salario mínimo a 751 euros al mes, una medida que destroza la competitividad del país, que carece precisamente de un sector productivo eficiente, y que solo puede competir salarialmente. Los salarios tienen su origen en la producción y en la productividad, no en decretos o en órdenes ministeriales. El único

${ }^{41}$ Plutarco, Vidas paralelas, Solon, 2, 3. Hesiodo (en torno al 700 a.C. fue un poeta de la antigua Grecia. Su padre era un pequeño comerciante en Cumas y se dedicó junto a el a labrar tierras. Autor de la Teogonía o genealogía de los dioses. 
sistema de elevar los salarios es fomentando el ahorro y el libre ejercicio de la actividad empresarial, porque la riqueza y el bienestar son consecuencia de la producción, no de la restricción.

En materia de política fiscal, como la elevación a un $75 \%$ del impuesto sobre la renta, la subida del impuesto de sociedades a las grandes empresas, la creación de un impuesto sobre el lujo o gravar las transacciones financieras, van en la misma línea, que no es otra que acentuar el intervencionismo económico. Ningún impuesto es neutro, disminuyen el bienestar de los consumidores y el ahorro de los empresarios, lo que afecta al consumo y a la futura dotación de bienes de capital. Distorsionan la cantidad y la distribución de lo que se produce, y cualquier impuesto que grava los beneficios empresariales impide que lleguen las señales que indican a los empresarios dónde invertir, además de dañar gravemente la soberanía del consumidor.

Otra de las medidas más señaladas del programa electoral de Syriza exigía una auditoría de la deuda y un cambio en el papel del BCE para que este financiara directamente a los Estados y a los programas de inversión pública. Estos programas se han mostrado todos claramente ineficientes, ahondan la ya de por si sobrecapacidad de la economía, no tienen impacto alguno sobre el empleo, pero sobre todo, son una fuente inagotable de corrupción. La corrupción da lugar a que ciertos grupos de personas o colectivos se enriquezcan a costa de otros, lo que al final provoca un desajuste social ya que los ciudadanos descubren que es más fácil obtener beneficios defraudando y desobedeciendo las leyes que cumpliendo las obligaciones, fomentando la creación de redes clientelares y grupos de presión, sobre los cuales Syriza y la partitocracia griega son un buen ejemplo de todo ello, o incluso el mismo Pericles.

Perciles y Alexis Tsipras representan, en la distancia del tiempo, ejemplos de una sistemática política populista. Y es que en una comunidad donde el populismo supone la guía intelectual, no hay sitio para la libertad. Si el gobierno es el único patrono, que designa a cada uno la tarea que ha de realizar, no puede haber libertad para elegir un negocio, un oficio, y lo que es más importante, no puede haber libertad para la creación de empresas ni respeto por la propiedad privada. Si el gobierno tiene poder para fijar las condiciones en las que se ha de trabajar, los salarios e incluso el lugar en el que 
cada uno ha de trabajar, no se puede generar empleo. Si además, el gobierno es dueño de casi todos los medios de comunicación, la capacidad de crítica social, control y por lo tanto fiscalización se diluye.

Pericles, al igual que Tsipras, buscan el control sobre las asambleas de ciudadanos y la coacción institucional sistemática, ofreciendo dietas, subsidios y planes de inversión pública para garantizar la paz social y la permanencia en el poder, terminan en la transformación de un estado productivo a un estado asistencial, eliminando el incentivo a la generación de riqueza y por lo tanto del libre ejercicio de la empresarialidad. Los ciudadanos griegos del siglo v a.C. y de la Grecia actual, como consecuencia de todas estas políticas, pierden el hábito de seguir las normas y principios para tratar de evitar los efectos perjudiciales de los mandatos coactivos del poder, que concede privilegios y ventajas o entrega bienes y servicios a cambio de paz social. El resultado es una mayor descoordinación social y un retraso económico, tecnológico y social. La Atenas de Pericles entró en conflicto con Esparta por el control del poder en Grecia, la Grecia actual se debate entre salir o permanecer en el euro y un futuro cada vez más incierto.

\section{VI CONCLUSIONES}

Las crisis son el origen de transformaciones económicas y políticas. A una situación de crisis se llega siempre por algún tipo de desequilibrio o desajuste económico, pero en todos los casos hay que tener presente el papel del Estado en las depresiones económicas. Por ello, es evidente el paralelismo que hay entre la Grecia de Pericles y de Tsipras, donde se manifiesta una hipertrofia del Estado, principalmente en la inversión y gasto público y sobre el intervencionismo económico.

En medio de esta situación de crisis, han aparecido en Europa una serie de partidos con un marcado perfil populista, defendiendo aumentos salariales, jornadas de trabajo reducidas, mayores prestaciones sociales y en definitiva una serie de programas llamados de bienestar social. Desde luego, quien quiera establecer un buen go- 
bierno, razonable y perdurable, debe empezar por intentar persuadir a sus ciudadanos de abrazar ideologías sensatas, y esto es justo lo contrario que hacen los gobernantes actuales de Grecia. Mensajes como que el capitalismo es injusto, que hay una minoría rica y la propiedad privada perjudica, que es necesario sustituir a los empresarios por el control gubernamental de la economía, o establecer un sistema de precios máximos y salarios mínimos, se oyen constantemente como soluciones para la crisis. Y sobre todo, es más necesaria que nunca una política monetaria generosa, capaz de expandir el crédito para aliviar las cargas impuestas por el capital a las masas y mutualizar la deuda. En definitiva, cuando se recurre a la violencia, a la coacción y a la compulsión en vez de recurrir a la persuasión, el gobierno de Syriza no hace mas que demostrar su propia incapacidad para resolver una situación tan compleja como la actual.

El euro representa una oportunidad para Grecia. La disciplina que exige el euro es beneficiosa para sus ciudadanos, ya que actúa como una poderosa barrera frente a proyectos demagógicos que no demanda la sociedad y que no se pueden financiar. Cuando los problemas asociados a estos proyectos se manifiestan en toda su crudeza, entonces los Estados se ven forzados a emprender reformas estructurales, que no son otras que reducir el gasto público y el estado del bienestar, al no poder esconder los problemas a costa de agravarlos. Antes tenían el recurso a la devaluación de sus monedas, ahora el euro lo impide, por lo tanto, es el euro el que está actuando contra las burocracias estatales, contra las castas políticas, los sectores privilegiados y los monopolios y grupos de interés, contra los subsidios y las redes clientelares y corruptas, y no los mismos políticos que ofrecen proyectos ineficientes. Sin duda, la permanencia en el euro de Grecia garantiza su futuro, siempre que esta se aleje de falsos populismos.

\section{REFERENCIAS BIBLIOGRÁFICAS}

Bengtson, H. (1986): Historia de Grecia, Madrid, Editorial Gredos. Bowra, C. (2003) La Atenas de Pericles, Alianza Editorial Diodoro Siculo (2001), Biblioteca Histórica, Madrid, Editorial Gredos. 
EHrenberG, Victor L. (1967) From Solon to Socrates, Routledge Fernandez Uriel, Pilar (2014) Historia Antigua Universal, El mundo griego, Universidad Nacional de Educación a Distancia HAYEK, F. (1990): La fatal arrogancia, los errores del socialismo, Madrid, Unión Editorial.

Herodoto de Halicarnaso (2000) Historias, Madrid, Editorial Gredos.

HuerTa DE Soto, J. (2011) Socialismo, cálculo económico y función empresarial, Madrid, Unión Editorial.

JebB, Richard C. (1890) The Attic Orators, McMillanKAGAN,

Kagan, Donald, (1990) The Archidamian war, Cornell University Press

LANE Fox, R. (2007): El mundo clásico, Barcelona, Editorial Crítica.

Menger, CARL (2014), El dinero, Unión Editorial.

- (2006) El método de las ciencias sociales, Unión Editorial

Mises, L. VON (2004): La acción humana, Madrid, Unión Editorial.

- (2011): La mentalidad anticapitalista, Madrid, Unión Editorial.

- (2010): Nación, Estado y economía, Madrid, Unión Editorial.

Platón (1981), Diálogos, Editorial Gredos

Tucidides (2006) Historia de la Guerra del Peloponeso, Madrid, Editorial Gredos.

- (2009) Discurso fúnebre de Pericles, Ediciones Sequitur Plutarco (1996) Vidas paralelas, Madrid, Editorial Gredos.

Ruden, SARAH (2003) Lysistrata, Hackett Publising

VV.AA. (2002): La Grecia Clásica 500-323 a.C., Historia de Europa Oxford, Barcelona, Editorial Crítica. 